\title{
DESIGN AND IMPLEMENTATION OF MICROSENSOR SYSTEM
}

\author{
Chii-Wann Lin ${ }^{1}$, Shao-Cheng Wang ${ }^{2}$, Oscal T.-C. Chen ${ }^{3}$, Sandy Wang ${ }^{3}$ \\ ${ }^{1}$ Center for Biomed Eng, Coll. Med., Natl. Taiwan Univ., Taipei, Taiwan, R.O.C. \\ ${ }^{2}$ EE Dept., Natl. Taiwan Univ., Taipei, Taiwan, R.O.C. \\ ${ }^{3}$ EE Dept., Natl. Chung Cheng Univ., Chia-Yi, Taiwan, R.O.C. \\ 'E-mail: cwlin@cbme.mc.ntu.edu.tw
}

\begin{abstract}
The design, implementation and characterization of a microsensor system for electrochemical measurements are introduced. This microsensor system consists of an electrochemical cell, amplifier, switches for miniature applications. Currently, we use a single ship microprocessor (80C51), an ADC (ADC0804) and seven-segment display for portable instrument prototype. The proposed microsensor is implemented by using the UMC $0.5 \mathrm{u}$ CMOS technology with a die size of $1.0 \mathrm{~mm} \times 1.0 \mathrm{~mm}$. The electrode area is $600 \mathrm{ux}$ $800 \mathrm{u}$. The unique design of a feedback voltage controlled resistor allows a flexible dynamic range for linear conversion of the induced current in various applications.
\end{abstract}

\section{Introduction}

The effective cost of a microsensor totally depends on its employed mass-production technologies. As the available methods, screen printing [1], thin film [2] and silicon technologies [3] have all been used in the past with some successful examples in the real world [4-6]. Together they provide numerous novel devices for better performance and faster turn-around time in clinical diagnostic and therapies [7]. Even though there are still quality control issues to be addressed with standard Si-technology processes, it attracts a lot of focus for the possible biomedical applications ranging from physical sensors to chemical ones $[4,8,9]$. The potential small size, low cost, high precision, and good reproducibility can significantly contribute to the quality of health care with smart design for better performance $[10,11]$. The same technologies can also meet the increasing demands in food industries, environmental monitoring and process control [12]. In this paper, we report an amperometric microsensor for possible medial applications. The flexible design of electrodes is explored with the amplifying and compensating circuitry. The unique architecture of this microsensor enables two-electrode or three-electrode configuration with a pass-transistor control and provides a flexible dynamic range adjustment for the induced current by a voltage-control resistor. The integrated device of microelectrode, current-to-voltage amplifier, voltage-control resistor, operational amplifier, and pass-transistor is designed, simulated and fabricated as the front-end smart device. The analog output is then digitized by an analog-to-digital converter (ADC0804) which interfaces to a single chip controller (8051) for post processing and data reporting via seven segment display.

\section{Methods}

The designed microsensor consists of an electrochemical cell, a current-to-voltage amplifier, a voltage-controlled resistor, an operational amplifier, and four pass-transistor switches as shown in figure 1 .

The induced current of amperometric method can be derived according to the following equation,

where

$$
\begin{aligned}
& \mathrm{I}_{\mathrm{f}}=\mathrm{n}^{*} \mathrm{~F}^{*} \mathrm{~A}^{*} \mathrm{D}_{\mathrm{o}}{ }^{*}(\mathrm{~d}[\mathrm{O}] / \mathrm{dx}) \\
& \mathrm{n}: \text { valence number } \\
& \mathrm{F}: \text { Faraday constant } \\
& A \text { : Area } \\
& \text { Do: Diffusion coefficient } \\
& \text { [O]: Oxygen concentration }
\end{aligned}
$$

With the constrains of total area on Si-substrate, the scale-down electrode area is about $0.48 \mathrm{~mm}^{2}$ which will induce $0-300 \mathrm{nA}$ current with glucose range from 0 to 12.5 $\mathrm{mM}$.

The reference and working/counter electrodes are implemented by using $\mathrm{Ag}$ and $\mathrm{Pt}$, respectively. They are realized by using photolithography and vacuum etching on Metal-2 layer of standard CMOS technologies. The circuitry of a current-to-voltage amplifier, a voltage-control resistor, an operational amplifier, and four pass-transistor switches is also implemented on the same substrate to fabricate an integrated microsensor as the front-end device for measurement system.

The analog output of this front-end device is then fed into an ADC (ADC0804) for 8 bits digital conversion. The output data is interfaced to a low power consumption single chip controller $(80 \mathrm{C} 51)$ for further processes which include storage, calibration, and report. Three seven-segment displays are used to report the data for range from 0 to $5 \mathrm{~V}$ with two decimal precision,

\section{Results}

The partial cross section of this microelectrode is shown in figure 2. A folded-cascade operational amplifier with a negative feedback voltage-controlled resistor is realized for the conversion of the induced currents to a reliable analog voltage output. At a control voltage of $1 \mathrm{~V}$, the HSPICE 
circuits simulation results in linear conversion of input current with sensitivity of $6.4 \mathrm{mV} / \mathrm{nA}$ as shown in figure 3 . Its equivalent impedance is $5.8 \mathrm{M}$ Ohm. The feedback voltage-controlled resistor has an impedance increase rate of $2 \mathrm{M} \mathrm{Ohm} / \mathrm{V}$ of its control voltage. The operation of two or three electrodes can be controlled through external registration. The proposed microsensor as shown in figure 4 is implemented by using the UMC $0.5 \mathrm{u}$ CMOS technology. The total electrode area is $600 \mathrm{u} \times 800 \mathrm{u}$ for the deposition of enzyme layer after its partial package and return to the laboratory. With the designed specifications, the induced current range can be effectively measured based on the two-electrode operation at a control voltage of $1 \mathrm{~V}$. The maximum output voltage for blood glucose detection is about $1.8 \mathrm{~V}$. The single-chip controller with three seven-segment display circuit is shown as in figure 5 .

\section{Discussions}

A microsensor system is designed and realized by using $0.5 \mathrm{uM}$ standard CMOS technology and a single chip controller for post-processing of data. There are a few technical issues which can be addressed for further development. First of all, post-modification of the microsensor with existing cleanroom technologies needs to put in more efforts to improve the yield rate. Secondly, self-calibration procedure is important for the performance of microsensor system and needs to integrate as a part of the hardware or software. Thirdly, the post data processing module needs to implement with low power consumption consideration to increase the durability of the microsensor system.

\section{Conclusions}

A unique architecture of microsensor is proposed and fabricated which enables two-electrode or three-electrode configuration with a pass-transistor control and provides a flexible dynamic range adjustment for the induced current by a voltage-control resistor. This integrated microsensor is designed, simulated and fabricated as the front-end smart device for biomedical applications using amperometric method.

\section{Acknowledgments}

This work is supported in part by National Science Council, Taiwan, R.O.C.

\section{References}

[1] R. Nagata, K. Yokoyama, S. A. Clark and I. Karube, "A glucose sensor fabricated by the screen printing technique." Biosensors \& Bioelectronics 10, 261-267 1995.

[2] O. J. Prohaska, F. Olcaytug, F. Kohl, G. Urban, W. Chu, R. Vollmer and J. LaManna, Medical Applications of Miniaturized Chamber-type Electrochemical Sensors. In Microsensors and Catheter-Based Imaging Technology (SPIE
Proceedings v. 904). (Ed. A. I. West) pp. 13-16, SPIE, Bellingham, WA 1988.

[3] O. T.-C. Chen, S. Wang, C. -W. Lin and Y. -C. Lu, A medical microsensor for blood glucose monitoring. ISCAS'97 Hong Kong (1996). (Abstract)

[4] E. Kress-Rogers, Handbook of biosensors and electronic noses: medicine, food and the environment, CRC Press, 1997. [5] H. M. McConnell, J. C. Owicki, J. W. Parce, D. L. Miller, G. T. Baxter, H. G. Wada and S. Pitchford, "The cytosensor microphysiometer: biological applications of silicon technology." Sci. 257, 1906-1912 1992.

[6] F. Scheller and F. Schubert, Biosensors, Elsevier Science Publisher, Amsterdam 1992.

[7] J. H. Nichols, C. Howard, K. Loman, C. Miller, D. Nyberg and D. W. Chan, "Laboratory and bedside evaluation of portable glucose meters." Am J Clin Pathol 103, 244-251 1995.

[8] M. Adami, M. Martini and L. Piras, "Characterization and enzymatic application of a redox potential biosensor based on a silicon transducer." Biosensors \& Bioelectronics 10, 633-638 1995 .

[9] C. Nicolini, M. Lanzi, P. Accossato, A. Fanigliulo, F. Mattioli and A. Martelli, "A silicon-based biosensor for real-time toxicity testing in normal versus cancer liver cells." Biosensers \& Bioelectronics 10, 723-733 1995.

[10] U. Fischer, S. Alcock and A. P. F. Turner, "Assessment of devices for in vivo monitoring of chemical species." Biosensors \& Bioelectronics 10, xxiii-xiv 1995.

[11] I. Moser, G. Jobst, E. Aschauer, P. Svasek, M. Varahram, G. Urban, V. A. Zanin, G. Y. Tjoutrina, A. V. Zharikova and T. T. Berezov, "Miniaturized thin film glutamate and glutamine biosensors." Biosensors \& Bioelectronics 10, 527-532 1995.

[12] R. Hintsche, M. Paeschke, U. Wollenberger, U. Schnakenberg, B. Wagner and T. Lisec, "Microelectrode arrays and application to biosensing devices." Biosensors \& Bioelectronics 9, 697-705 1994.

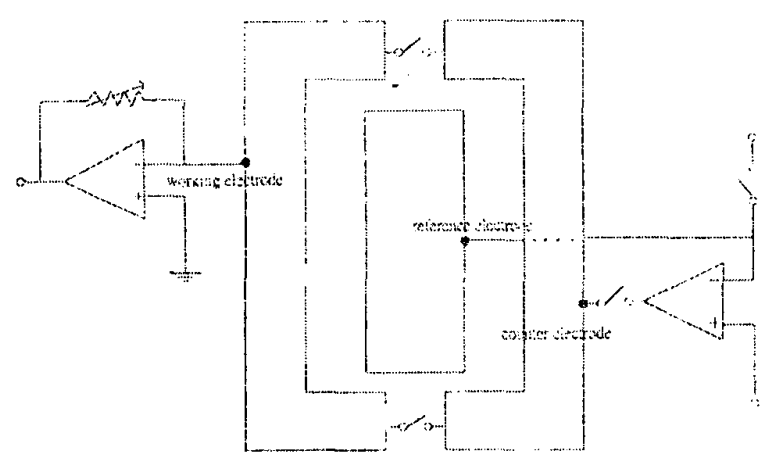

Figure 1. Schematic diagram of the proposed microsensor 
Proceedings - 19th International Conference - IEEE/EMBS Oct. 30 - Nov. 2, 1997 Chicago, IL. USA

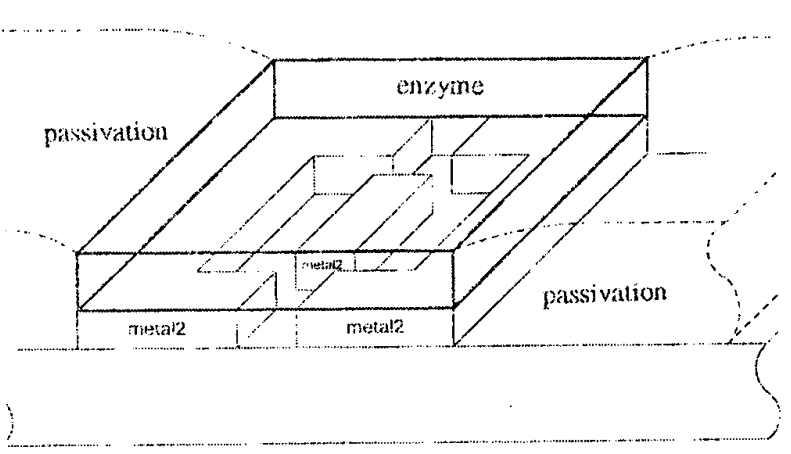

Figure 2. Partial cross section view of electrode area

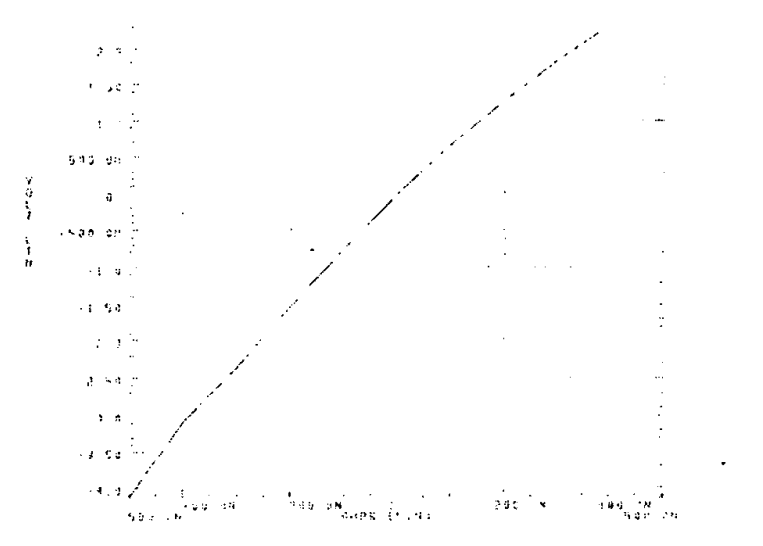

Figure 3. The HSPICE simulation result of the current-to-voltage amplifier.

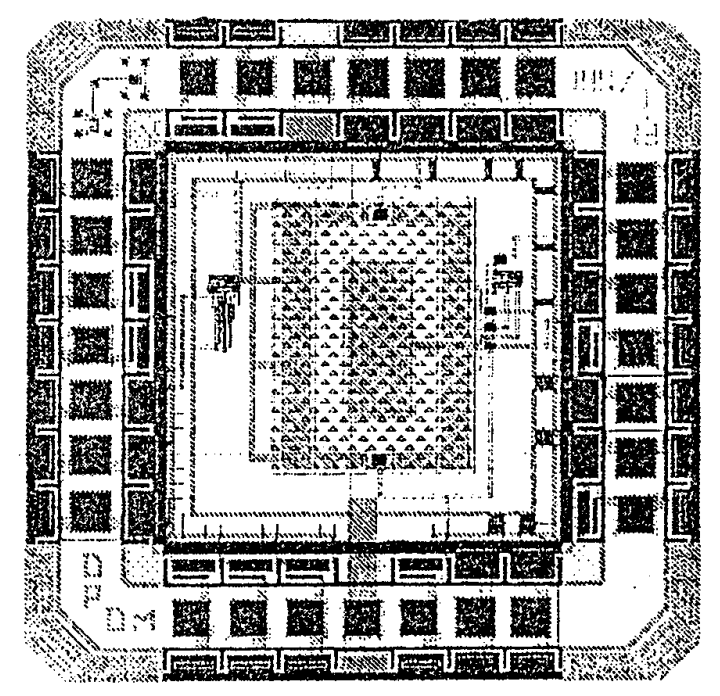

Figure 4. The top-view of the microsensor system layout.

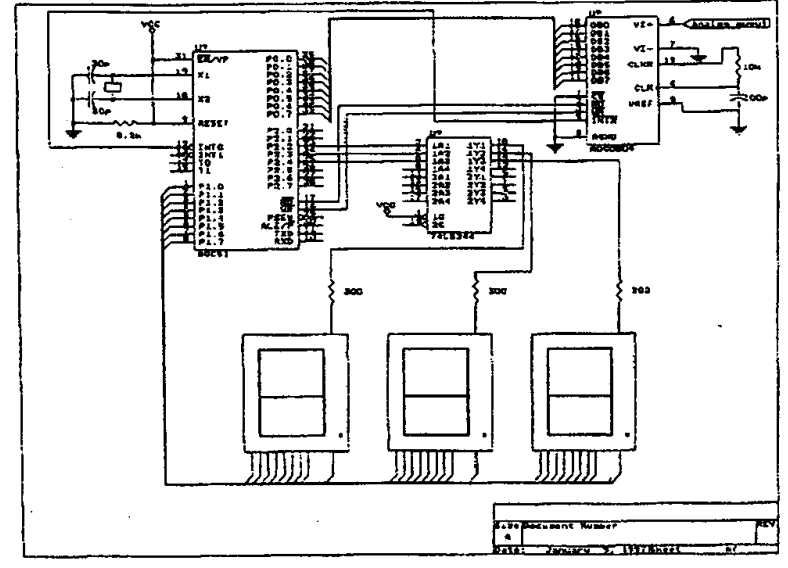

Figure 5. Schematic diagram of single-chip controller and $\mathrm{ADC}$ for microsensor applications. 